\title{
PELATIHAN APLIKASI AKADEMIK RAPOR ONLINE BERBASIS WEB SEBAGAI ALAT BANTU MONITORING HASIL BELAJAR SISWA (STUDI KASUS: MADRASAH ALIYAH NEGERI 12 JAKARTA)
}

\author{
Jatnika, $\mathrm{H}^{* 1}$; Rifa'i, M.F ${ }^{2}$; Fitriani, ${ }^{3}$; Irfansyah P., R. ${ }^{4}$; Kusuma, Dine T. ${ }^{5}$; \\ Sudirman, Yoga D. M. ${ }^{6}$; Purwanto, Y.P. ${ }^{7}$; Supriadi, Amanda T. ${ }^{8}$ \\ 1,2,3,4,5,6,7,8 Sekolah Tinggi Teknik - PLN Jakarta \\ Teknik Informatika \\ e-mail: ${ }^{* 1}$ h.jatnika@sttpln.ac.id
}

\begin{abstract}
Abstrak
Untuk mendukung upaya pemerintah dalam memajukan kesejahteraan rakyat dan menjadikan bangsa terpelajar, dan juga menjadikan salah satu misi STT-PLN untuk meningkatkan pendidikan, penelitian, dan kegiatan pengabdian masyarakat, tim P2M memiliki perjanjian untuk meningkatkan $\begin{array}{llllll}\text { layanan pendidikan } & \text { di } & \text { MAN } & 12 & \text { Jakarta. }\end{array}$ Sebagai kelanjutan P2M sebelumnya, tim berfokus pada pelatihan administrator laporan online berbasis web. Aplikasi ini dibangun oleh tim dan disebut SIROMADU, singkatan dari Sistem Informasi Rapor Online Terpadu. Tujuan dari P2M adalah untuk membantu MAN 12 Jakarta untuk beradaptasi dan memanfaatkan pengembangan teknologi informasi untuk memudahkan beberapa proses yang dilakukan secara manual sebelumnya, yang pada akhirnya akan meningkatkan kualitas layanan MAN 12 Jakarta. Targetnya adalah membuat MAN 12 Jakarta untuk dapat menerapkan dan memiliki kemampuan untuk mengoperasikan dan mengelola program aplikasi SIROMADU. Ini juga akan melatih administrator departemen teknologi informasi di MAN 12 Jakarta.
\end{abstract}

Kata kunci: pelatihan, SIROMADU, MAN 12 Jakarta

\section{Abstract}

In order to suppor the government's efforts at advancing the people's prosperity and to make an educated the nation, and also to make one of the missions of STT-PLN to improve the education, research, and community service activities, the P2M team has an agreement to improve the education services at MAN 12 Jakarta.

As the continuity of the previous $P 2 M$, the team focuses on the training of the web-based online report administrators. This application was built by the team and called SIROMADU, an abbreviation of Sistem Informasi Rapor Online Terpadu. 
The goal of the P2M is to help the MAN 12 Jakarta to adapt and make use of the information technology development to ease some process which was manually done before, which at the end will improve the service quality of the MAN 12 Jakarta.

The target is to make MAN 12 Jakarta to be able to implement and has the ability to operate and manage the SIROMADU application program. It will also train the administrator of information technology department at MAN 12 Jakarta.

Keywords: training, SIROMADU, MAN 12 Jakarta

\section{PENDAHULUAN}

Undang - undang No 12 Tahun 2012 tentang pendidikan tinggi mewajibkan semua perguruan tinggi yang ada di Indonesia untuk menyelenggarakan pendidikan, penelitian, dan pengabdian kepada masyarakat. Pada pasal 1 No 11 menjelaskan bahwasanya Pengabdian kepada Masyarakat adalah kegiatan civitas akademika yang memanfaatkan Ilmu Pengetahuan dan Teknologi untuk memajukan kesejahteraan masyarakat dan mencerdaskan kehidupan bangsa. Adapun Dosen adalah pendidik profesional dan ilmuwan dengan tugas utama mentransformasikan, mengembangkan, dan menyebarluaskan Ilmu Pengetahuan dan Teknologi melalui Pendidikan, Penelitian, dan Pengabdian kepada Masyarakat.

Perguruan Tinggi berperan aktif menggalang kerja sama antar Perguruan Tinggi dan dengan dunia usaha, dunia industri, dan Masyarakat dalam bidang Penelitian dan Pengabdian kepada Masyarakat. Tujuan Pengabdian Pada Masyarakat (P2M) adalah mendekatkan lembaga pendidikan dengan masyarakat, sehingga perguruan tinggi dapat membantu pemerintah dalam mempercepat gerak pembangunan dan mempersiapkan kader-kader pelaku pembangunan yang berkualitas. Niat dan motivasi yang murni ialah secara ikhlas untuk mengabdi bagi kepentingan masyarakat dengan mengamalkan ilmu pengetahuan, teknologi, dan seni yang telah dikuasai, bukan karena kepentingan pribadi ataupun mencari keuntungan materi.

Sebagai kelanjutan dari kegiatan P2M sebelumnya, yaitu membuat rancang bangun aplikasi rapor online, tim P2M kemudian melakukan pelatihan kepada para administrator TI di MAN 12 Jakarta sebagai administrator aplikasi, agar mereka memiliki keahlian yang dibutuhkan untuk mengoperasikan dan mengelola penggunaan aplikasi ini di MAN 12 Jakarta.

Pengabdian kepada masyarakat yang akan dilaksanakan kali ini bertujuan untuk memperkenalkan dan memberikan pelatihan kepada tenaga pendidik/guru untuk dapat meningkatkan pelayanan kepada siswa secara cepat, dalam hal ini mendapat nilai sekaligus memudahkan guru-guru dalam mengisikan rapor secara online. Dalam tahapan pengolahan hasil proses belajar mengajar yang selama ini, Madrasah Aliyah Negeri 12 Jakarta masih 
menggunakan aplikasi Microsoft Excel, adapun proses mengolah data nilai tersebut dilakukan dengan cara menghitung jumlah rata-rata nilai ulangan, kemudian dicarikan hasil akhir nilai siswa selama satu semester yang sedang berjalan. Sedangkan didalam memasukkan nilai siswa sering terjadi kesalahan sehingga harus mengulang kembali untuk mencari nilai akhir.

Permasalahan yang dihadapi oleh Madarasah Aliyah Negri 12 Jakarta saat ini, yaitu belum adanya sistem yang terintgerasi yang bisa mengakomodir semua kegiatan hasil belajar siswa/siswi dan diakses secara cepat oleh pihak sekolah maupun oleh wali murid. Dalam rangka mendukung hal tersebut, pada periode P2M sebelumnya dibuatkan rancangan sistem informasi akademik rapor online yang ditidaklanjuti dengan pelatihan aplikasi tersebut pada periode $\mathrm{P} 2 \mathrm{M}$ yang akan berjalan saat ini.

Mitra masyarakat yang akan bekerjasama melaksanakan program kemitraan masyarakat (PKM) adalah Madarasah Aliyah Negri 12 Jakarta, sesuai dengan perjanjian sebelumnya di Madarasah Aliyah Negri 12 Jakarta belum memiliki sistem informasi rapor online yang dapat diakses oleh yang berkentingan, adapun target dari kegiatan ini adalah:

1. Madarasah Aliyah Negri 12 Jakarta dapat memberikan informasi rapaor secara online

2. Siswa didik dapat mengakses informasi online secara cepat dimanapun berada

3. Orang tua siswa dapat mengontrol dan memonitoring pencapaian belajar siswa didik.

Pelatihan ini dilakukan untuk menyiapkan para administrator TI di Madrasah Aliyah

Negeri 12 Jakarta agar dapat menjalankan tugasnya sebagai pengelola SIROMADU MAN 12 Jakarta yang sudah dibangun oleh tim P2M STT-PLN, yang mencakup, tapi tidak terbatas pada:

- Mengelola penggunaan aplikasi SIROMADU untuk staf, pengajar, siswa dan wali murid.

- Memahami fitur-fitur yang tersedia pada aplikasi.

- Melakukan dan memonitor pengisian dan pemutakhiran data di SIROMADU.

- Mengetahui langkah-langkah yang harus dilakukan, termasuk pihak-pihak yang dapat dihubungi sebagai support, saat perlu melakukan troubleshooting terhadap aplikasi SIROMADU.

Pelatihan yang dirancang oleh tim P2M akan dilakukan setelah tim selesai menyempurnakan aplikasi SIROMADU dan menyiapkan modul-modul pelatihan yang terdiri dari:

- Modul Akademik, terdiri dari data akademik dan mata pelajaran

- Modul Pembelajaran, terdiri dari Data Guru Mata Pelajaran dan Data Siswa

- Modul Penilaian, yang terdiri dari penilaian ekstrakurikuler, kehadiran, prestasi, kompetensi dasar, dan nilai mata pelajaran.

- Serta menu cetak rapor. 


\section{METODE PELAKSANAAN}

\subsection{PESERTA}

Peserta pelatihan adalah para administrator TI di Madrasah Aliyah Negeri 12 Jakarta. Pelatihan ini bertujuan untuk:

1. Memberikan pelatihan kepada Tenaga Pengajar/Guru dan Wali Murid MAN 12 Jakarta tentang penggunaan Aplikasi Rapor Online.

2. Memberikan pemahaman tentang Aplikasi Rapor Online kepada Tenaga Pengajar/Guru dan Wali Murid MAN 12 Jakarta untuk dapat meningkatkan pelayanan kepada siswa.

3. Diharapkan dengan program aplikasi yang dibuat dapat mempermudah dalam proses pengolahan data nilai rapor siswa agar lebih cepat.

4. Mempermudah dalam proses penyajian laporan hasil belajar siswa kepada wali murid yang bersangkutan.

5. Mengenalkan STT PLN khususnya Jurusan Teknik Informatika kepada Tenaga Pengajar/Guru MAN 12 Jakarta sebagai salah satu bentuk promosi kepada siswa/i MAN 12 Jakarta

\subsection{RANCANGAN SOLUSI}

Dalam rangka untuk meneyelesaikan permasalahan terkait belum terlatihnya masayarakat sekitar Madarasah Aliyah Negri 12 Jakarta dalam hal sistem rapor online rancangan solusi yang ditawarkan untuk mengatasi masalah tersebut adalah:

1. Kreatifitas dalam pembuatan laporan siswa secara online

Dapat membuat berbagai macam variasi dan bentuk pelaporan hasil belajar siswa/siswi dari tools dan fitur-fitur yang tersedia pada aplikasi kepada Tenaga Pengajar/Guru MAN 12 Jakarta.

2. Terlatih dalam menggunakan sistem informasi aplikasi online

Dengan aplikasi yang bisa diakses secara online, dapat menyesuaikan dengan perkembangan teknologi saat ini.

3. Mendapatkan berbagai ilmu saat menggunakan aplikasi Tenaga pengajar/Guru MAN 12 Jakarta

\subsection{METODE PELATIHAN}

Metode pelaksanaan yang dilakukan pada pelatihan ini adalah:

1. Mengumpulkan informasi mengenai kebutuhan spesifik mitra Madrasah Aliyah Negeri 12 Jakarta untuk aplikasi SIROMADU, melalui serangkaian percakapan dan diskusi saat proses rancang bangun aplikasi berlangsung serta dari beberapa pertemuan lainnya dengan pihak-pihak inti MAN 12 Jakarta.

2. Merancang modul dan teknik pelatihan yang sesuai dengan kebutuhan mitra, berdasarkan fitur-fitur yang ada pada aplikasi dan hasil diskusi dengan mitra. 
3. Melaksanakan pelatihan sesuai jadwal yang telah disepakati antara tim dan mitra.

4. Membuat laporan pertanggungjawaban pelaksanaan P2M.

\section{HASIL DAN PEMBAHASAN}

\subsection{HASIL}

Bagi kelompok sasaran, dapat memiliki sistem rapor online sehingga pihak Madrasah Aliyah Negeri 12 Jakarta dapat memberikan informasi secara cepat, monitoring orang tua siswa terhadap pencapaian pembelajaran anak dapat realtime dan informasi rapor diterima oleh murid dapat diakses kapanpaun

1. Bagi Tim P2M dapat mempraktikan ilmu serta keterampilan yang dimiliki khususnya bidang Informatika kompetensi Sitem Informasi dan Rekayasa Perangkat Lunak

2. Bagi STT-PLN dapat meningkatkan Citra STT-PLN dimasyarakat umum dalam rangka meningkatkan kualitas hidup masyarakat, serta mempererat hubungan anatara civitas akademika STT-PLN dan warga masyarakat khususnya Madrasah Aliyah Negeri 12 Jakarta.

Pelatihan penggunan rapor online di Madarasah Aliyah Negri 12 Jakarta akan dilakukan dalam satu sesi yang akan diikuti oleh sekitar 20 peserta yang akan dibagi ke dalam beberapa kelompok. Kegiatan ini dapat dilaksanakan dalam jangka waktu sekurangkurangnya empat hari kerja . Setiap peserta akan diberikan materi berupa pengetahuan, keterampilan, dan tes uji secara mandiri.

Langkah 1 : Peserta pelatihan diberikan teori tentang dasar-dasar aplikasi rapor online, teknik perawatan aplikasi, dan teknik pengoperasian aplikasi rapor online tersebut

Langkah 2 : Setelah mendapatkan teori tentang teknik pengoperasian aplikasi, setiap peserta diminta untuk mempraktikkan secara langsung teknik pengoperasian termasuk apabila ada troubleshooting.

Langkah 3 : Setiap peserta secara berkelompok akan diuji melakukan kegiatan pengoperasian aplikasi rapor online

Langkah 4 : Setiap peserta secara berkelompok diminta melakukan praktek cara-cara pengoperasian aplikasi rapor online

Langkah 5 : Setiap peserta setelah melakukan praktek pengoperasian aplikasi, akan diuji secara tertulis untuk mengetahui tingkat kompetensi dan keterampilannya setelah mengikuti pelatihan.

Langkah 6 : Peserta yang sudah selesai mengikuti pelatihan dan uji mandiri dianggap mampu mengoperasionalkan sistem informasi rapor online 


\subsection{DOKUMENTASI KEGIATAN}

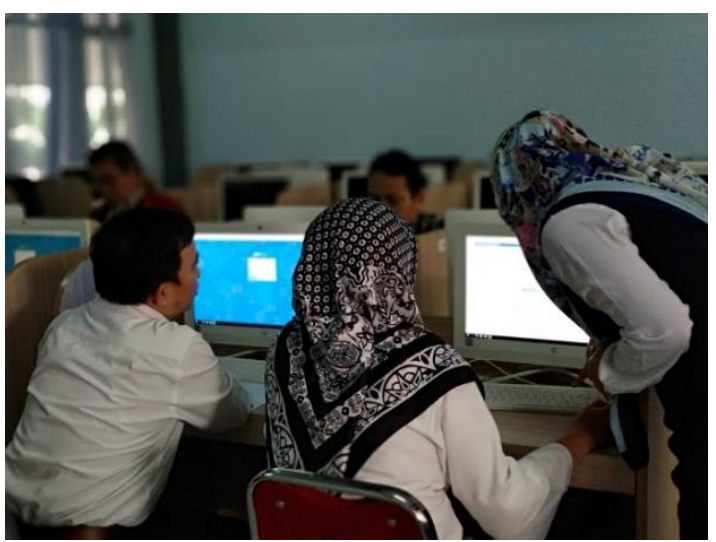

Gambar 1. Pelatihan penggunaan aplikasi Rapor Online

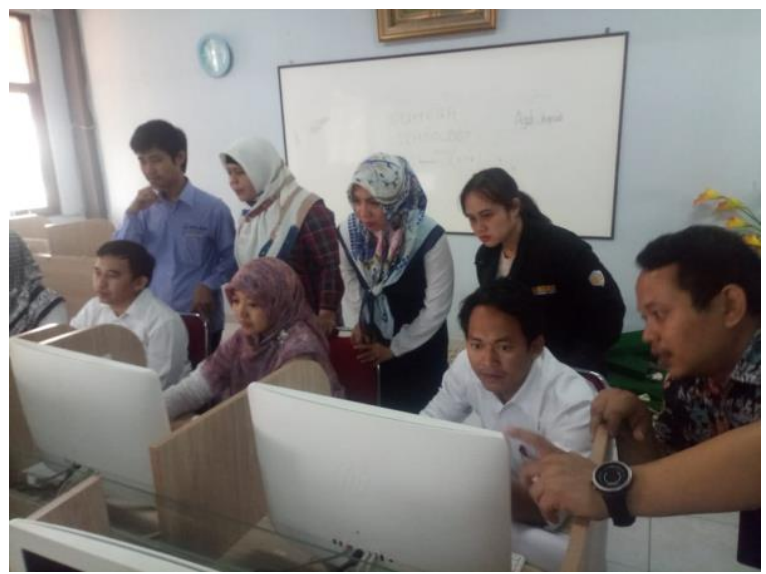

Gambar 2. Simulasi penggunaan penggunaan aplikasi Rapor Online

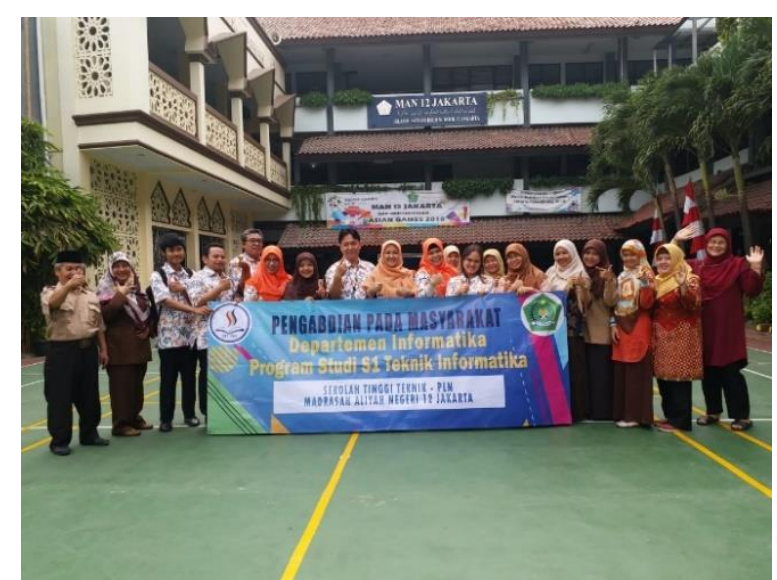

Gambar 3. Penutupan Pelatihan penggunaan aplikasi Rapor Online 


\section{KESIMPULAN}

Kegiatan P2M yang berfokus pada kegiatan pelatihan bagi para administrator TI di Madrasah Aliyah Negeri 12 Jakarta dilaksanakan dengan sukses dan lancar. Kegiatan pelatihan berhasil dilaksanakan pada tanggal 28 Agustus 2018.

Saat pelatihan berlangsung, didapat hasil observasi tim dan feedback dari peserta pelatihan beberapa temuan sebagai berikut:

- Madrasah Aliyah Negeri 12 Jakarta saat ini menggunakan domain dari pihak ketiga yang juga berperan sebagai pengelola domain dan web developer situs MAN 12 Jakarta.

- MAN 12 Jakarta tidak dapat secara efektif memanfaatkan website mereka saat ini, salah satunya karena terbatasnya kapasitas domain. Ini menyebabkan mereka tidak bisa mengupdate informasi yang mereka butuhkan (misalnya, mengupload foto-foto kegiatan) ke dalam website.

Berdasarkan temuan di atas, tim P2M beserta pimpinan MAN 12 Jakarta (Dra. Herawati., M.pd) telah setuju untuk mengatasi permasalahan tersebut pada kegiatan P2M selanjutnya.

Kegiatan P2M ini ditutup pada tanggal 29 Agustus 2018, dihadiri oleh ketua dan seluruh anggota tim P2M serta Ibu (mohon masukkan nama bu Kepsek) selaku Kepala Sekolah Madrasah Aliyah Negeri 12 Jakarta, dan Ibu Dinar (Dinar Inayah., S.Pd) selaku (Tim Kurikulum).

Mitra kami, Madrasah Aliyah Negeri 12 Jakarta, menyatakan kepuasan mereka terhadap hasil dan pelatihan yang dilakukan oleh tim P2M, dan mereka menyambut baik kesempatan untuk melanjutkan kerja sama dengan tim P2M.

\section{SARAN}

Pelatihan penggunaan aplikasi yang dilakukan oleh tim PKM STT-PLN dalam penggunaan rapor online bagi sekolah dapat memberi dampak positif dan ini merupan langkah kecil namun memberi nilai yang sangat besar. Untuk itu, apa yang sudah dilakukan dalam kegiatan pengabdian masyarakat ini, dapat dilanjutkan pada semester depan dengan pengembangan aplikasi yang lain.

\section{UCAPAN TERIMA KASIH}

Penulis mengucapkan terima kasih kepada STT-PLN dan Madrasah Aliyah Negeri 12 Jakarta yang telah memberikan dukungan dan bantuan sehingga pelaksanaan kegiatan program kemitraan masyarakat ini dapat terselenggara dengan lancar. 


\section{DAFTAR PUSTAKA}

[1] Spewak, Steven H,.Steven C.Hill, (1992). Enterprise Architecture Planning : Developing a Blueprint of Data Application and Technology, John Wiley and Sons, Inc.

[2] Porter, Michael E, Competitive Advantage: Creating and Sustaining Superior Performance for Analyzing Industries and Competitor, 1985

[3] Ward, John and Peppard, Joe., Strategic Planning for Information System, John Wiley \& Sons, Inc., 2002 